\title{
COSAS QUE OCURRIERON EN LA PARROQUIA DE VILLAFRANCA (NAVARRA) EN LOS SIGLOS XVI Y XVII
}

POR

\author{
JosÉ ANTONIO MARCELLÁN
}

\section{RESUMEN}

Vida de una pequeña parroquia navarra durante los dos primeros siglos de la Edad Modema, que sirve de ejercicio de microhistoria para conocer la vida cotidiana de estos siglos en una comunidad nural del Antiguo Régimen.

\begin{abstract}
Life of a small parish of Navarra during the two first centuries of the Modern Age, that serves as an exercise of microhistory to know the daily life of these centuries in a rural community of the Ancien Regime.
\end{abstract}

En septiembre de 1997 se cumplieron los quinientos años de la construcción del actual templo parroquial. Con ese motivo he recogido algunos datos de la vida parroquial en los siglos XVI y XVII que nos pueden ayudar a comprender a aquellos que nos precedieron en la fe, con sus luces y sombras.

\section{LOS COFRADES SE ENFADAN}

Las organizaciones de seglares en aquellos tiempos se integraban preferentemente en las cofradías y, a veces, como en esta ocasión, se dieron tensiones con la jerarquía: 
«El alcalde y mayorales de las cofradías de Santa Maria y San Pedro de Villafranca expusieron al Consejo Real que, siendo las cofradias una sociedad y compañia hecha entre personas legas para ciertos actos de devoción y siendo las personas legas y su hacienda también lega, el obispo de Pamplona se quería entremeter a pedirles cuenta de los bienes de la cofradía. Habiendo apelado de un mandato que les dió y estando bajo la apelación al metropolitano de Zaragoza, les había puesto entredicho y hacía dos meses que los tenía sin misas ni divinos oficios, en lo cual el pueblo recibía agravio, mayormente en aquel tiempo en que se acercaban las fiestas de Pascua. Pidieron las mandase otorgar la apelación y levantar el entredicho $o$ al menos suspenderlo hasta primas causas para que se viese la razón que tenían ambas partes y no quedase el pueblo sin misas ni divinos oficios en las fiestas de Pascuan ${ }^{1}$.

Lo que está claro por este documento escrito, es que la gente del pueblo expresa por medio de sus autoridades locales, la preocupación de encontrarse en una situación desagradable, como consecuencia de los arrebatos y sin razones de unos y otros. Por encima de la marejada de pasiones que se dieron de una parte y de otra, para llegar a esa situación, lo que preocupa al pueblo es no poder celebrar, como es debido, las fiestas pascuales.

Eh aquí una manifestación clara de la fe de aquellas buenas gentes, que tenian su amor propio, pero que estaban dispuestos a abrir una tregua y a buscar caminos de entendimiento, reconociendo implícitamente que había alguna razón en el castigo.

Con estos dimes y diretes el templo ya se había levantado y siguieron haciéndose ampliaciones y reformas en el edificio:

«(...) y no cree fuera por la ampliación de la Iglesia porque dicha se hizo el año 1549 con permiso de D. Antonio de Fonseca y se acabó de pagar el affo de 1550 pues con las rentas principales de dcha. Iglesia, con permiso de D. Alvaro de Atoscosso, los dos obispos de Pamplona, y no hay vestigio ni seffal en dcha. Iglesia, ni lo ha oido decir a los mayores, había habido otra ampliación que la referida a la sacristía que se hizo el afio 1567, con permiso también de D. Diego Remírez de Sedeño, obispo también de Pamplona y la capilla de San Francisco de Asís, que también se hizo después de 1570 (...) $)^{2}$.

De esta época también es el libro de las constituciones del Cabildo eclesiástico de Villafranca, "formadas y confirmadas 1567 ).

Para satisfacer la curiosidad del lector interesado copio alguna de ellas:

«1. Puntualidad.- Porque si todos vienen tarde ¿quien principiará el officio?

5. Itten que el vicario y benefficiados en las missas y visperas tengan silencio en la Iglesia y piensen y mediten en aquello que cantan orrezan y el un coro no principie a cantar o rezar antes que el otro aya acabado el verso.

1 José GoNi GazTaMBDE, Historia de los obispos de Pamplona, Tomo III, p. 327.

2 Archivo diocesano. Ref. Villanueva $\mathrm{C} / 1.777, \mathrm{n}^{\circ} 15$, folio 135. 
6. (...) que el cantar y salmear se haga con sossiego y buen concierto.

11. Henque nadie cantando seassome (o arime al antepecho del coro ni otro ninguno se pasee por el coro entre tal que se hacen los divinos officios...).»

\section{LA ENCERRONA EN LA IGLESIA}

Precisamente por causa de las obras en una de las capillas, nos encontramos con otra curiosa anécdota:

«Por entonces se decian "trentenas reveladas" en la Iglesia de Villafranca, permaneciendo los clérigos encerrados durante los treinta dias" ${ }^{3}$.

El Espasa-Calpe dice sobre la palabra «Treintenario»:

«Se daban tres formas de Treintenario:

1) El treintenario encerrado: Número de 30 misas que se decian en sufragio de un difunto, por espacio de treinta dias seguidos, permaneciendo el celebrante encerrado en la Iglesia.

2) Treintenario llano: Número de 30 misas celebradas en 30 días seguidos por el alma de un difunto.

3) Treintenario revelado: Número de 30 misas que se declan por espacio de $\mathbf{3 0}$ dfas seguidos en sufragio de un difunto, estando durante ellos encerrado el sacerdote en la iglesia, haciendo algunos ejercicios, en virtud de lo cual, se creía superticiosamente que Dios había revelado al fin el estado del alma del difunto.»

Nadie está libre de cometer errores y no es extrafio que a veces se mezcle la $\mathrm{fe}$, con alguna superstición.

La costumbre de celebrar treinta misas seguidas por un difunto ha llegado hasta nuestros días con el nombre "gregorianas» porque las estableció el Papa $\mathrm{S}$. Gregorio y a ellas se les atribuye una intercesión especial de este santo, aunque no tienen aneja ninguna indulgencia especial.

Tampoco contamos en la Iglesia con el procedimiento de averigiar cual es el estado del alma de un difunto, por muchas encerronas que se hagan.

Śblo conocemos el estado del alma de aquellos difuntos que han sido beatificados o canonizados por la Iglesia.

${ }^{3}$ José GoNi GazTamBIDE, op. cit., Tomo 1li, p. 556. En nota a este texto se dice lo siguiente: Ibid., carpeta de Villafranca. Pleito entre el vicario y los beneficiados de la Iglesia de Sta. Engracia (!) de Villafranca, y Juan Vallés tesorero de Navarra, sobre el demolitorio de cierta obra en una capilla, 1555, hojas 93, f. 37 v. Cf. Enciclopedia universal ilustrada europeo-americana, Espasa-Calpe, sub voce treintenario revelado. 


\section{UN CLÉRIGO DE VILLAFRANCA EN EL CONCLIO DE TRENTO}

Por estos años se hizo famoso un clérigo de Villafranca, nada menos que echando un discurso en la tercera sesión del concilio de Trento. Nos lo cuenta D. José Goñi Gaztambide, cuya obra es una fuente generosa para este trabajo:

«El día 3 de junio de 1563, fiesta de la Santísma Trinidad, Oronsuspe tuvo el honor de dirigir la palabra a todo el concilio, congregado en la catedral de la ciudad, Sin rayar a la altura de Carranza, salió airoso de la demanda.

¿Quién era este teólogo y orador que así dejó oír su voz en aquella augusta asamblea? Nació y fue bautizado en la parroquia de S. Pedro de Olite (Navarra) por el año 1533, ya que el 4 de junio de 1573 declaró tener $\mathbf{4 0}$ afoos de edad. Más tarde fue racionero en la misma iglesia. El 22 de diciembre de 1556 el obispo de Pamplona, Álvaro de Moscoso, concedió "reverendas de grados, epístola, evangelio y misa para Miguel de Oronsuspe, natural de Olite, residente en París". Era entonces clérigo de prima tonsura, beneficiado de la iglesia de Villafranca y bachiller en teologia. Se alojaba "in colegio Plesii". Alli se doctoró en teología para el año $1558{ }^{4}$.

La disertación de Oronsuspe fue sobre el sacramento del orden referido a los obispos y llegó a los oídos de S. Carlos Borromeo, secretario del papa Pío IV. Oronsuspe fue luego canónigo y tuvo sus pequeños líos en el Cabildo de Pamplona. Hasta fue encarcelado. No fue este el único clérigo de Villafranca que llegó a canónigo de Pamplona. Hubo otros, como Juan Mariano Bobadilla, natural de Villafranca, aunque racionero en Cascante, pero esto ocurria mucho tiempo más tarde, en el año $1820^{5}$. Aunque hay que reconocer que la mayoría de los clérigos de Villafranca no aspiraban a canónigos y se encontraban bastante satisfechos con su beneficio en la parroquia, cuyas obligaciones procuraban cumplir, con algunos fallos, como es normal.

Aquel mismo año de 1563 se celebraron juntas generales en Cestona y Segura y dos años más tarde en Villafranca y en ellas se acordó pedir al rey Felipe II que solicitase del papa la incorporación a la sede de Pamplona de todos los pueblos españoles sometidos al obispo de Bayona (El Baztán y Cinco Villas), ante el peligro de la propaganda calvinista ${ }^{6}$.

\section{La corraliza de PeÑa Alfons (¿s. IX?)}

Esta es una historia de buen entendimiento entre el Ayuntamiento y la Parroquia. Resulta que por el año 1692 los vecinos cedieron la corraliza... «por 500

\footnotetext{
4 José GoñI GaztamBIDE, op. cit., Tomo IV, páp. 44 y ss.

5 José Goñ GaztamBide, op. cit, Tomo IX, p. 271.

6 José GoNI GAzTAMBIDE, op. cit., Tomo IV, pág. 214.
} 
ducados quede efectos de dicha Iglesia les entregaron para ocurrir a diferentes gastos con que el presente se hallaban (...) desde cuyo tiempo a acá está percibiendo la dicha Iglesia el producto anual de la referida corraliza (...) y hallándose como se hallan dichos vecinos precisados a disponer crecidas cantidades para ocurrir a las muchas fábricas que se han de ofrecer con motivo de dar nueva madre al río Aragón y gastos de litigios con las villas de Peralta y Funes, por estar mandado por el Real y digno Consejo que las fábricas se hagan a costa de expedientes y efectos de vecinos y siendo el referido de la corraliza uno de los mejores efectos determinen y resuelvan el modo de rescatarla y empeñarla para el referido efecto, $y$ atendido la dicha proposición todos los vecinos unánimes y conformes dijeron dar y otorgar todo su poder cumplido y bastante (...))\%.

Así se acordó en sesión del Ayuntamiento celebrada el 24 de agosto de 1749, para lo que presentan un memorial al obispo, D. Gaspar de Miranda y Argaiz, que resuelve a favor de la petición a los cinco días, el 29 de agosto de 1749 .

Posteriormente se reunen el Cabildo parroquial y el Ayuntamiento el 1 de septiembre, para que se lleve a ejecución el decreto.

El Ayuntamiento paga los 500 ducados a la Parroquia con fecha del 3 de septiembre del mismo año y a la parroquia le vienen muy bien porque está empeñada en 1962 ducados en que se ha estimado la construcción de la torre.

\section{LAS ERMITAS}

De algunas de ellas poco podemos decir, por ejemplo de la de santa María Magdalena, que se situó al suroeste de la Villa, dando cara a Milagro. En el libro de visitas pastorales de 1805 se dice que la ermita dependía del monasterio cisterciense de Nuestra Señora de la Blanca de Marcilla. En 1763 hubo un pleito entre estos monjes y el vicario de Villafranca, Fernando Muñoz y Olloqui, por denuncia de éste ante el obispado sobre el mal estado en que se encontraba la ermita que se había convertido en "choza y albergue de bagamundos y establo de ganados, cometiendo abominables exzesos..."

Los monjes y en su nombre Simón Puyal y Artaso prior, se defienden diciendo que no era la cosa para tanto. Además protestan porque el vicario fue con un herrero y descerrajó la puerta. Por fin se ordena que se limpie la ermita y que se distinga bien el lugar del culto del resto donde se pueda hacer otro uso. Por estos documentos sabemos que había una imagen de Santa María Magdalena, de S. Bernardo, S. Sebastián y coronándolo todo un Santo Cristo. Se dice también que distaba de la Villa más de media legua y del monasterio legua y media ${ }^{7}$.

\footnotetext{
${ }^{2}$ Archivo dioc. Ref. Navarto $\mathrm{C} / 2.264, \mathrm{n},{ }^{\circ} 12$.
} 
Gonzalo López, vecino, me informa que tenia el estilo de un fortín árabe y su construcción se ubicaba muy cerca de la estación del tren de Milagro en el término de la Dehesa. El 24 de junio era su fiesta y se celebraba con meriendas y música.

La de S. Pedro

«Es un edificio del s. XVI, aunque se halla muy retocado en la actualidad» ${ }^{8}$.

Pienso que en la actualidad necesita algún retoque más, sobre todo en su tejado. Parece que hay algún proyecto a efectuar en su entorno, un pequeño parque. La ermita y el lugar donde está se lo merecen, sobre todo, teniendo en cuenta que es la única que queda fuera del pueblo.

La de Santa María del Castellar

De ella nos dice el vecino Gonzalo López: «Su deterioro llegó en los años 1930 a tal estado que unido a la desidia del pueblo, se optó por el camino más fácil de la piqueta y quedó reducida a un solar, para nuestra vergüenza.»

LA IMAGEN DE SANTA EUfEMIa

En el libro primero de Primicia (1596-1623) nos encontramos con un dato interesante respecto a la imagen de Santa Eufemia que lleva fecha del 22 de noviembre de 1597:

«A Ambrosio de Bengoechea entallador, por la imagen de Santa Eufemia, 16 ducados, y más a Juan de Frías, pintor por dorar, 12 ducados, más el mensajero que fue por la imagen con una cabalgadura, gastos y jornales, 12 reales. Total 24 ducados y 1 real.,"

Todo es poco para una imagen tan bella que adorna con su grandiosidad el retablo.

Tal vez la labor del entallador se refiera a la imagen del busto de la Santa, que se encuentra en el lado de la epístola.

En 1700 y en el mismo libro de las primicias, nos encontramos con un documento curioso referido a la devoción a Sta. Eufemia y a su imagen :

${ }^{8}$ M. C. García Gainza y col., Catálogo monumental de Navarra, merindad de Tudela, p. 438.

Actas del I Congreso de Historia de la Iglesia y el Mundo Hispánico

Hispania Sacra, 52 (2000) 
"Auto donde consta haber dado a la Iglesia Dn. Jerónimo Fernández en nombre de D. Agustín de Bertiz caballero de la orden de $\mathrm{S}$. Juan y comendador de la encomienda de esta villa, una colgaduras para el adomo de la capilla mayor de dicha iglesia en cuyo altar está colocada la Sefiora Santa Eufemia su patrona de brocateles en seis trozos forrados los de a cuatro bernas cada uno y los cuatro de a tres junto con una carta del tenor siguiente: Muy ilustres Sefiores, el Comendador Dn. Agustín de Bertiz caballero de la orden de San Juan muy a fecto a Vas. Expone a su noticia la propension reverente en que se halla a cuanto mira el mayor culto del templo a nuestra gloriosa patrona Santa Eufemia e impelido del mismo hallándome con una tapicería nueva de brocaletes de Turin los presento a Vuestras Sefiorías para que por hijos tan propios de tan célebre patrona sea dedicada como lo hago con sumo gusto para su capilia mayor $y$ todas las festividades del Redentor y la Reina de los Angeles y Apóstoles y de que se preste para la celebración de Nuestra Seffora del Portal: seffores por esta demostración de mi afecto reconocerán Vas. los eficaces deseos de mi reconocimiento ratificándome en el mismo Villafranca a 5 de diciembre de 1700 su mayor servidor que sus M.B. Dn. Agustín de Bertiz...»

\section{Petición en fayor del convento de Puente la Reina}

El 4 de marzo de 1604, en la visita pastoral que hace el obispo de Pamplona, fray Mateo de Burgos, ordena:

«Iten se manda al Vicario que nombre luego un hombre abonado para que pida limosna por la iglesia con un vacin todos los domingos y fiesta de guardar para las religiosas monjas del convento de Sancti Spiritus de la villa del Puente de la Reyna, quienes padecen extrema necesidad y estan rogando a Dios Ntro. seffor con mucho fervor por los bienhechores : el cual dicho vacin ha de andar en cuatro afios y en tercer lugar después de la Redempcion segun las provisiones en esta razon despahacda y todo lo que en cada un año se cogiere lo cobre el dicho vicario para enviar a la priora del dicho convento o a la persona por ella nombrada en la cual se le encarga el cuidado y la conciencias (Libro $1^{\circ}$ de primicia 1596-1623).

\section{LOS PRIMEROS TRILLIZOS DE VILLAFRANCA}

Fue el seis de abril de 1606 cuando nacen los primeros trillizos: Ana, Benito y Pedro, hijos de Pedro y María, que llegaron a tener hasta doce hijos (Libro 3 de bautizados, folio 38 vto. y siguientes).

Eran otros tiempos en los que no había tanto dinero, pero sí más generosidad. A pesar de todo, ni faltaba el pan, ni la alegría. O sería tal vez por eso.

\section{OTRA HISTORIA DE CLÉRIGOS}

Algo más de un siglo después -era por el año 1671-nos encontramos con nueva anécdota referida a otro clérigo de Villafranca. Se hallaba el obispo de Pamplona, Pedro Roche de visita pastoral en Peralta, 
«(...) cuando recibió una petición que le llenó de consuelo. Francisco Ambrosio López Varnuevo, presbitero y beneficiado de Villafranca de Navarra, por parecerle cosa muy del servicio de Dios el encaminar las almas a la virtud y exhortarlas a penitencia, desea andar por algunos lugares de este obispado a ensefiar a los rudos la doctrina cristiana y que por falta de maestros no estén muchos en grave peligro de sus almas, y también predicar exhortando a la penitencia y a la virtud, que por ser una de las principales vocaciones a que Dios lo llama, desea no resistir su voluntad»" ${ }^{9}$.

Por lo que podemos sacar la conclusión de que en Villafranca, no sólo había clérigos sabios, sino también santos. Por supuesto que habría algunos pecadores.

\section{La Basilica de Nutstra Señora del Portal}

El nombre hace pensar en un pueblo amurallado. Villafranca había sido destruida en las luchas de los agramonteses contra los beaumonteses. A finales del s. XV se reedifica, pero de tal manera que las casas unidas unas a otras sean como un prolongado muro hacia afuera con dos portales uno al NO, el portal del Cristo, por donde salía el rebafio vacuno a pastar al soto y el otro el dedicado a la Virgen y del que vamos a hablar al $S E^{10}$. Entre el uno y el otro había y hay un túnel desde la calle verde a la calle del muro. También por eso el ángulo sur del pueblo que mira hacia la ermita de S. Pedro se le llama «El Portillo», como si fuera un corte o una brecha en las murallas.

En relación a la cofradía que tenía encomendado el hospital, situado precisamente junto a la Basilica del Portal hay un documento fechado en 5 de agosto de 1793 y firmado por Manuel Bartolomé Ros, presbítero que, a propósito de aclarar su obligaciones respecto a la capellanía que regenta, nos da una serie de datos de la remota antigíedad de algunas cofradías y de la fundación del hospital:

«Por encargo de los srs mayordomos y cofrades de la Cofradía nombrada de Santa Maria del Castellar, San Pedro y Sta. Eufemia, que comunmente llaman la Cofradía del Hospital, ha examinado su Regla, o Constituciones, Libros y demás Papeles, con el fin de indagar el principio y fundación de la Capellanía de la Misa de Once, que por encargo de la Cofradía se celebra todos los domingos en la Parroquia de esta villa de Villafranca. Esta diligencia se ha practicado para cumplir con el Decreto general del Tribunal Eclesiástico de este Obispado, por el que se manda, que los Capellanes o Patronos presenten a los Parrocos una copia de la fundación de sus respectivas Capellanias.

\footnotetext{
${ }^{9}$ José Goñ Gaztambide, op. cit., Tomo VI, pág. 364

to Félix M. Martinez, S. Celedonio y M. Jesús Lacarra Yanguas, Historia de Villafranca de Navarra, p. 248.
}

Actas del I Congreso de Historia de la Iglesia y el Mundo Hispánico

Hispania Sacra, 52 (2000) 
Y después de examinadas dichas Constituciones, Libros y Papeles, hallo que la Cofradía de Santa María del Castellar, y la Cofradia de San Pedro Apostol y santa Eufemia, fueron Cofradías distintas, cuyas constituciones se aprobaron separadamente por el rey Carlos de Navarra en el año 1355 y desde ese tiempo corrieron governandose cada Cofradía por si sola, hasta que en el de 1686, viendo que ambas Cofradias observaban un mismo instituto, y que empleaban sus rentas, y limosnas en la asistencia, y alivio de los pobres enfermos del Hospital; que era propio de las dos Cofradías, pretendieton de conformidad en el Tribunal Eclesiastico de este Obispado la unión de ambas, representando las grandes utilidades, que de esta unión se havian de seguir en conocido beneficio del Santo Hospital de esta Villa: y efectivamente obtuvieron decreto favorable, que se halla en el libro que regía aquel año.

En la regla de cada Cofradia se hace mención del Abad, que tenía obligación de decir Misa solemne el día que llamaron del Sitio, que, segun yo entiendo, era un dia sefalado, en que cada affo se juntaban los cofrades; pero no se descubre que toviera otra carga de Misas, ni estipendio alguno, sino que, según parece, era uno de los Cofrades empleados assi como el Alcalde y mayordomo. Es de notar que el Libro mas antiguo, que ha quedado de la Cofradía de San Pedro, empieza en 1606 y el más antiguo de la Cofradía de santa María en 1531.»

Parece que la alusión al «Sitio» se refiere a una batalla que tuvieron que arrostrar los navarros frente a los castellanos en octubre de 1335 y en la que Cadreita, Alfaro y Valtierra lo pasaron peor. Los de Villafranca pudieron resistir el asalto ${ }^{11}$.

Por el escrito de este clérigo vemos que las cofradías que dedicaban parte de sus fines a la atención de los difuntos, se fueron abriendo a las necesidades de los vivos en obras de caridad con los enfermos, particularmente con los más pobres. Hubo dramas colectivos que obligaron a ello como la peste negra que invadió a Villafranca en 1348 e hizo tales estragos que de 87 fuegos que había en la villa de pasó a 46. Más tarde en los siglos XVIII y XIX hubo muchas guerras y se impuso la necesidad de atender a los soldados heridos ${ }^{12}$.

En la primavera de 1690 nos encontramos en Villafranca con un hecho interesante. Resulta que D. Diego Polo, residente en Indias, dona quinientos pesos a D. Bonifacio de Arlés, presbítero de Villafranca y con esos dineros y 4.000 reales, que se sacan de alguna venta y limosnas, se llegan a reunir hasta 850 ducados. El alcalde y regidores, "con autoridad propia y sin licencia de su Excia. Illma. han pretendido añadir un pedazo a otra Basílica».

Existía ya «el templo de la Virgen de El Portal, llamado así por haber estado situado junto a una de las puertas de la Villa, es un edificio del siglo XVI» ${ }^{13}$. La

\footnotetext{
"I Félix M. Martinez San Celedono y M. Jesús Lacarra Yanguas, Historia de Villafranca de Navarra, pp. 193-195.

12 Félix M. Martinez, S. Celedonio y M. Jesús Lacarra Yanguas, op. cit, pp. 363 y ss.

13 María Concepción Garcta Gainza y cols., Catalogo monumental de Navarra, I Merindad de Tudela, p. 435.
} 
obra, por lo que parece, se inició con la intención de ampliar el templo ya construído.

El 16 de mayo se manda detener las obras por orden del Vicario general del Obispado. La obra la estaba realizando Antonio de Olea, maestro albanfil,vecino de Alfaro y su ayudante Blas Antonio reclama doscientos ducados por los daños ocasionados por la detención de las obras.

Se contrata a Pedro Aguirre y José Ezquerra, maestros albañiles, «arquitectos vezinos de las ciudades de Tudela y Corella» que examinan la obra e imponen algunas reformas.

Hay nuevas protestas, ahora por parte de la Villa: se dice que lo que ha hecho José Aguirre no se debe apreciar, por ser hecho sin consentimiento de la Villa. Antes no se había contado con el Obispado, ahora no se cuenta con el Ayuntamiento. Cada uno sale por sus fueros, como es lógico.

Se calcula lo hecho por los anteriores en 1950 reales, a los que hay que descontar lo que hubiere vencido. También hay quejas respecto a la obra realizada por Damián Romeo Iturbugui que empezó a trabajar el 2 de abril.

El 3 de junio de 1690 se dicta sentencia favorable desde el Obispado a seguir las obras por parte del Ayuntamiento, siempre que se concedan «al mejor postorm. Se exponen las condiciones en que se ha de efectuar. Luego hay una posterior nota del Obispado de fecha 13 de octubre de 1691 en que se dice que la obra realizada por Damián Romeo está bien hecha y se concede al Ayuntamiento permiso para vender bienes por valor de 300 ducados con el fin de rematarla.

Estos bienes cuya venta se autoriza desde el Obispado serían propiedad de alguna cofradía, porque sólo en ese caso se requeriría el permiso ${ }^{14}$.

En 1810 se traslada el hospital al convento de los Carmelitas, entonces cerrado por la invasión napoleónica. Eh aquí la carta por la que se pide el traslado:

«Manuel Benito de Echevertia, Procurador de la Cofradía de Nuestra Seffora del Castellar, y San Pedro, patrona del hospital de la villa de Villafranca de este Reyno de Navarra, digo que como esta fábrica se encuentra situido en la parte mas concurrida del Pueblo, yen la unica Plaza publica donde se venden todos los comestibles, y a los que concurren frecuentemente las gentes con el objeto de proporcionar undesaogo a sus tareas y ocupaciones diarias, viendo en la actualidad desocupado el combento de religiosos carmelitas descalzos a resultas de la estincion a este instituto ha solicitado y obtenido la Cofradia mi parte de los Sefiores Vocales de la seccion del interior del Reyno la gracia deque se puedan trasladar los enfermos y establecer el Hospital en el referido Combento hasta que llegue el caso de que se venda entre las Fincas Nacionales o qu el govierno le de algun otro destino todo con el objeto de evitar al Publico los perjuicios que podian resultarle de la existencia del Hospital en el parage en que ha estado. Como parece del

14 Archivo diocesano. Ref. Lanz C/1.167 n." 5.

Actas del I Congreso de Historia de la Iglesia y el Mundo Hispánico Hispania Sacra, 52 (2000) 
despacho que exive. La Iglesia del combento ha estado y esta cerrada, pero para el alivio y consuelo espiritual de los enfermos Combalecientes del Hospital y de todos los sirbientes, empleados en el sera muy util su apertura, pudiendose celebrar el santo Sacrificio de la Misa y demas oficios divinos en lo que interesaran tambien los demas fieles del Pueblo que quieran aprovecharse de esa buena proporcion. La vida de la Iglesia quedara al cargo del Hospital y de d. Juan Pastor Presbítero exreligioso del mismo Combento de Carmelitas Descalzos. Y en este concepto y a fin de que puedan tener cumplido efecto los buenos deseos de la Cofradia

Suplico a V. S. se sirva conceder su facultad para que desde luego se abra la enunciada Iglesia del Combento de Carmelitas descalzos pudiendose en ella celebrar el Santo Sacrificio de la Misa y demás funciones de culto consultando a la conbeniencia y beneficio espiritual delos enfermos del Hospital, sus dependientes y empleados y los demas fieles del Pueblo que quieran aprovecharse de semejante buena coyuntura y pido justicia.

Manuel Benito de Echeverrias ${ }^{15}$.

Como veremos más tarde los carmelitas volvieron en 1823 al convento; por lo que el Hospital volvió también en esa fecha a su antiguo emplazamiento.

\section{CONSTRUCCIÓN DE LA TORRE}

Desde la ventanilla del coche o del tren, en la panorámica de Villafranca, to que destaca es la torre, que es atalaya que amplía aún más el horizonte del pueblo. En su entorno de aire y de sol la torre de Villafranca, emergiendo sobre el edificio del templo, se eleva, sin almenas ni saeteras, porque no se ha hecho para defender, sino para indicar la ruta de las alturas y hacerse ver y oir. Desde la Bardena, trabajando la tierra o pastoreando el ganado, cuando ya no alcanza el oído, llega la vista hasta la torre lejana que es punto de referencia buscado y querido.

La torre, sobre todo, para albergar las campanas. Ya en la visita pastoral de 1597, el obispo de Pamplona, Dn. Antonio Zapata, les ordena entre otras cosas:

"Que el campanero $u$ otra persona por él, tafía cada día la campana de esta iglesia a la plegaria del medio día y a la avemaría un poco antes de que anochezca que es un poco después de puesto el sol y sea muy de día claro y no espere que anochezca..»

Pasan los años y con ellos las generaciones se suceden; pero la torre permanece allí. En ella se refugian las aves, bajo ella los vecinos elevan sus preces y corazones. Desde su altura llegan a la Villa los sonidos familiares que marcan fechas y recogen colectivos sentires cuando sus campanas doblan gordo o sue-

15 Archivo dioc. A/16 n, ${ }^{\circ} 108$.

Actas del I Congreso de Historia de la Iglesia y el Mundo Hispánico

Hispania Sacra, 52 (2000) 
nan débiles y quebradizas, proclamando llantos o gozos. También se tocaban las campanas por motivos más prosaicos:

«En la villa de Villafranca dentro de la Iglesia parroquial de señora santa Eufemia, miercoles a 14 días del mes de octubre del año 1609 habiéndose tañido la campana, pregonado por Juan Fernandez, nuncio y pregonero público de la dicha villa para que todos los que quisieren acudiesen a la dicha iglesia a ver pasar y recibir las cuentas de las primicias de la dicha villa...»

Ya es hora de recoger una descripción de la torre:

«Mención especial merece la fachada sur, que corre por el lado de la Epistola, donde se localiza la bella torre barroca y el pórtico, cuyas obras se llevaron a cabo a finales del siglo XVII, cuando todavía estaba en pie el templo del siglo XVI. La construcción de la torre se autorizo en 1692 y en este mismo af́o tenia hecha su traza Santiago Raón; a partir de aquí se iniciaron las obras bajo la dirección del maestro Pedro Aguirre y Loreaga, quien habia construido sus dos primeros cuerpos, más el pórtico adjunto para 1696. Los dos cuerpos restantes y el chapitel se hicieron posteriormente, con trazas de José Ezquerra; el tercero se construyó entre 1699 y 1700 por Antonio Olea.

La torre es de ladrillo, con basamento de piedra, y consta de tres cuerpos cúbicos y un cuarto octogonal que se remata por una balaustrada, según un recurso que el propio Exquerra llevó a cabo en la catedral de Tudela. Todos los cuerpos se articulan por pilastras cajeadas, múltiples en los dos inferiores, sobre las que montan las respectivas cornisas, que en el tercer y cuarto cuerpo incorporan labores de ladrillo entre triglifos. Completa la decoración de la torre una serie de motivos geométricos que se desarrollan en los basamentos y paîos de los cuerposs ${ }^{16}$.

Las citas que lleva esta descripción tienen como fuente el archivo parroquial. En ella no sólo se dan detalles de la construcción sino que también se hace historia de la misma.

A estos datos podemos añadir los siguientes: D. Andrés Garraza prior del cabildo eclesiástico de Villafranca y el Alcalde solicitan autorización para seguir construyendo la torre el 10 de septiembre de 1699.

Contaban con 1.000 ducados del Consejo real y la mitad de una viña y olivar dado a la Iglesia por D. Diego Garcfa de Olloqui y la otra mitad de lo que dejó a la capilla de la Madre de Dios del Rosario y las primicias. Se da licencia para que se inviertan en ella 1962 ducados y dos reales en que la obra es tasada por los peritos. La autorización lleva la firma de Diego de Echarren, gobernador y vicario general del obispado.

Es un periodo de sede vacante entre los obispos Toribio de Mier (1693-1698) y su sucesor Juan Iñiguez de Arnedo (1700-1710).

${ }^{16}$ Maria Concepción García Gainza, op. cit., I merindad de Tudela, p. 424.

Actas del I Congreso de Historia de la Iglesia y el Mundo Hispánico Hispania Sacra, 52 (2000) 
El constructor Pedro de Aguirre, después de hacer el segundo cuerpo, tuvo que interrumpir la obra: «Sucedió al dcho Pedro de Aguirre una desgracia por la qual salio obligado a retirarse a los Reinos de Castilla a donde se llevó la plantai) ${ }^{17}$.

Se entiende que lo que se llevó Pedro de Aguirre fueron los planos. A donde parece que fue es a Corella donde su padre estaba construyendo el chapitel de la Iglesia del Rosario, que se derribó y hubo de acudir su hijo a remediarlo, según me comunica verbalmente María Jesús Lacarra.

Por eso deseando los patronos continuar la obra «hizo otra planta del tercer y quarto cuerpo, que faltan amas del chapitel José Ezquera maestro de obras vecino de Tudela, que se comunicó con Pedro José de Falces, capuchino, maestro de mucha ciencia enjenería y experiencia) ${ }^{18}$.

\section{LOS OCHOCIENTOS FOLIOS DE UN PLEITO INTERMINABLE}

Parece cosa de broma, pero es verdad.

$\mathrm{El}$ archivo diocesano conserva más de ochocientos folios de un pleito promovido por unos vecinos $u$ otros por causa de un decreto del Obispado que quiere acabar con la costumbre que tenían algunas mujeres de sentarse en las sepulturas «que ay encima de las gradas de la capilla maior de la Iglesia y poner en ella los affales, cera y otras tiendas..." ya que producen grandes inconvenientes y perjuicio y embarazo, así para la administración de sacramentos, como para celebrar los divinos oficios. La costumbre planteaba dificultades pues no quedaba espacio para las ceremonias, además del humo y la cera de las velas que salpicaban, las vestiduras talares, las ofrendas, etc.

El mandato se publicó solemnemente en el púlpito; pero era muy difícil de cumplir: se habian adquirido derechos por la costumbre, había rivalidades entre unas mujeres y otras por ocupar aquellos lugares y, sobre todo, se trataba de algo que afectaba muy vivamente a algunas familias linajudas. Era algo así como tocar a sus muertos.

Los afectados recurren contra aquel mandato $\mathrm{y}$, a su vez, el cabildo eclesiástico exige aquella reforma, absolutamente necesaria para el debido decoro de las ceremonias y para un buen acomodo de todos en la Iglesia y mejor participación en la liturgia.

\footnotetext{
${ }^{17}$ Archivo diocesano. Ref. Echalecu C/1.356, n. ${ }^{\circ} 22$, folio 24.

18 Arch. dioc. Ref. Echalecu C/ $1.356, n^{\circ} 22$. Estos datos están tomados de documentos distintos que se encuentran bajo la referencia citada.
}

Actas del I Congreso de Historia de la Iglesia y el Mundo Hispánico Hispania Sacra, 52 (2000) 
El pulso entre algunas familias linajudas y los cabildos eclesiastico y secular se mantiene con dominio alterno. En alguna ocasión parece que el pleito lo gana D. Francisco Arévalo Eguía y los tutores de D. Juan Jerónimo Martínez de Arizala que alegan tener las sepulturas con sus derechos inherentes desde tiempo inmemorial, por servicios prestados a la Iglesia y al rey y consiguen una sentencia favorable, con algunas limitaciones.

En otras ocasiones es tan contraria que llega hasta la excomunión formulada con toda solemnidad en estos términos:

«Nos el Doctor D. Juan de Echalar, prior y canónigo de la santa iglesia cathedral de esta ciudad, provisor y vicario general de este obispado de Pamplona por el Muy Ilustre Cavildo de la dcha cathedral, sede episcopal vacante

A vosotros los Rectores, Curas, Vicarios y Clérigos de el dcho. Obispado por la presente os mandamos, que notifiqueys a Joseph Camus prior de D. Francisco de Arebalo

Para que dentro de dos horas que de beningnidad le damos cumpla con lo que por nos le fuere mandado a instancia de los cavildos eclesiástico y secular de la villa de Villafranca,

Y no lo haziendo asi en vuestras Iglesias, y fuera de ellas, donde convenga, y fuere necessario, todos los domingos, y fiestas de guardar, passado el dicho termino, lo declarad, y denunciad por publico excomulgado, que Nos por la presente lo declaramos, y denunciamos por tal, y lo evitareis de los Divinos Oficios, y consorcio de los Fieles Christianos, y no lo admitays en ellos hasta que cumpla con lo que asi le fuere mandado, y de Nos obtenga beneficio de absolucion.

Dada en Pamplona a doce de Diciembre de mil seiscientos cincuenta y siete. Y se despacha por la Restitucion del pleyto de los mandatos de la Villa de Villafrancas ${ }^{19}$.

Parece que el tema se llevó demasiado lejos, aunque tendríamos que situarnos en aquel ambiente y en aquella sociedad, para comprender el sentido de estas medidas que, contrariando su propio significado, se convertían en desmesuradas.

La excomunión se manejaba entonces como arma muy convincente : bastaba con blandirla amenazante, para que muchos vinieran a mandamiento.

Los más de ochocientos folios manuscritos no se escribieron en un día : fue el trabajo de días y meses, de argumentos y contraargumentos, de idas y venidas de la Villa a la Curia episcopal y viceversa. Todo por mantenella y no emmendalla en aquellos dimes y diretes, dares y tomares. Los escribanos y abogados habrían hecho su negocio.

Por fin se puso orden y concierto en la Iglesia. El tema se venía arrastrando desde hacía muchos años. En la visita pastoral de 1599, realizada por Felipe de Obregón, en nombre del obispo se manda:

${ }^{19}$ Archivo diocesano, ref, Ollo $\mathrm{C} / 1005, \mathrm{n} .{ }^{\circ} 1$. 
«iten, los bancos y escaños de esta Iglesia, se hagan como el visitador lo ha ordenado, para que quede lugar para sentarse las mujeres debajo de ellos, a las cuales se manda... no se sienten entre los bancos ni escafios entre los hombres, si no fuere los nueve días cabo de año y día de los difuntos... y se procederá contra ellas con todo rigor, por la indecencia que hay en que se sienten a los pies de los hombres y por el escándalo que de ello se sigue... que ninguna mujer se siente de los dichos escafios adelante, y el alcalde, justicias y regimiento no lo consientan y el vicario y beneficiados cesen los oficios si pretendieren las dichas mujeres sentarse fuera de donde esta mandado....

En 1611 el visitador general Dn. Luis Venegas de Figueroa insiste:

«Por cuanto habemos visto cuan mal parejo está el suelo de la Iglesia y la necesidad que hay de solarse, mandamos que se suele lo más presto y despues de solada se haga cuenta de lo que costare y se reparta entre los duefios de las sepulturas conforme a cada uno le tocare pagando la Iglesia también..s

En 1614 el obispo, Fray Prudencio de Sandoval, manda también:

«Manda que con toda brevedad se allane y empareje el suelo de la dicha Iglesia pues está tan indecentemente y paguen los duefios de las sepulturas lo que les tocare.»

En el mismo sentido se ordena en 1620:

«Iten por cuanto el suelo de la dicha Iglesia esta en partes desenladrillado con indecencia mandamos se enladrille y allane en las partes que se hallare tener necesidad, a costa de los duefios de las sepulturas en las que se hallare haber la necesidad."

Pero esta propiedad y, a la vez responsabilidad sobre las sepulturas, no les autorizaba a enajenarlas:

«Iten porque podria haber que algunas personas por no saber o por ignorancia vendiesen por sus necesidades sepulturas que tienen en la dicha Iglesia no lo pudiendo ni debiendo hacer, por ser cosa eclesiástica y estar prohibido semejante ventas y donaciones, y ser simonia el hacerlo, mandamos...»

De nuevo el afio 1623:

«Iten manđo que las sepulturas se aderecen e igualen para que toda la Iglesia este igual y pareja como antes ha sido mandado."

El problema era mayor en las primeras gradas. Asi al dar las cuentas, los primicieros Francisco de Alcalá y Antonio de Vitoria de 1657-58, dicen:

"Iten da por descargo haber pagado ocho reales a un propio que fue a la villa de Mendigorria a llamar a Jorge Pérez y Juan de Heredia con orden de ambos cabildos eclesiástico y secular para que vinieran a esta a conferir el negocio de las sepulturas que hay sobre las primeras gradas y capilla mayor por ver si se podia ajustar y obrar el litigio de la

Actas del I Congreso de Historia de la Iglesia y el Mundo Hispánico

Hispania Sacra, $52(2000)$ 
dichas sepulturas..... y cumplimiento de unos autos de visita para que no se sienten mujeres de los primeros escaños arriba y en particular en las sepulturas de las primeras gradas del altar mayor, affales, cera ni candelas por el embarazo que hacen al culto divino en la celebracion de los oficios....

Era un conflicto de intereses: el interés mayor del culto y orden en la Iglesia y el menor de los derechos que se concedían sobre determinadas sepulturas a los familiares, unos derechos subordinados al general y no perpetuos, como se ve en esta concesión:

«a 12/12/1700 se le contesta y se le ofrece una sepultura en la iglesia apra el dicho xeronimo Fernández y María de Trepeana su mujer y Josefa de Leon su madre y suegra durante sus vidas, sentándose en ella y llevando candelas y enterrándose en ella como se fuesen muriendo como lo hacen y pueden hacer todos los que tienen sepulturas propias en dicha iglesia, sin limite ninguno con calidad de muertos los tres cese esta gracia y permisión.»

Como se ve, el tema venía de lejos y llovía sobre mojado.

\section{LA COFRADIA DEL Rosario}

Entre las numerosas cofradías de la parroquia llama la atención la del Rosario (1591) por las letrillas que de ella se conservan y porque pocos años antes -en 1572- había muerto San Pio V, de quien oí esta anécdota de niño: «Estaba rezando el rosario cuando le anunciaron la victoria de Lepanto.s

De un modo ingenuo recuerda este hecho una de las coplas de los auroros de Villafranca:

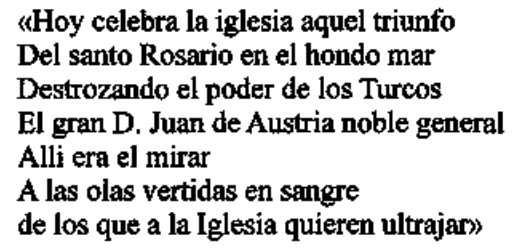

Bien podía ser verdad porque, como se sabe, S. Pío V era dominico y como fiel discípulo de Sto. Domingo, no sólo rezaba el rosario, sino que lo propagó entre los fieles. Cuando lo eligieron papa, después de alguna resistencia aceptó, pero diciendo que siempre vestiría el hábito de los dominicos. Desde entonces todos los papas van vestidos de blanco.

En Villafranca se conserva un folleto con el título de «Colección de Auroras de Villafranca" y en él hay coplas para todos los días del año. Una de ellas ya la ha leido el lector. 
El aire limpio de la mañana en el pueblo se rompe por un grito hecho canción, que es lamento, alegría, invitación y plegaria. Detrás de la música pegadiza hay toda una sabiduría popular amasada en creencias y experiencias, que se expresa y aflora desde las gargantas, desde el sentir y querer, desde la herencia de tantas generaciones. Verdades como puños, teología popular hecha vida en las costumbres, cantadas con alegría y con la seguridad de los que creen sin complicaciones. La música sirve a la letra y la letra lleva a Dios.

Mucho entusiasmo tenían que echarle estos madrugadores pregoneros para lograr, no sólo ser escuchados, sino convocar a los fieles a devoción tan hermosa, sintiéndose mensajeros de María:

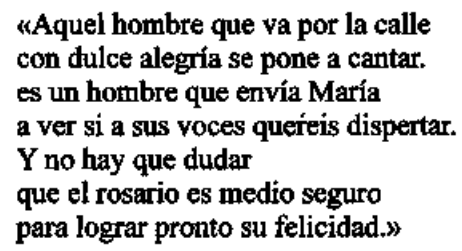

Sin embargo, la naturaleza humana es frágil y muchos días los auroros apenas obtenían respuesta satisfactoria del vecindario. Entonces se quejan:

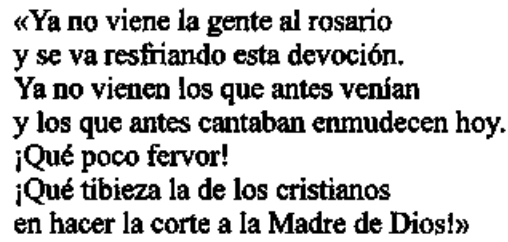

A pesar de todo, los auroros siguen constantes un día y otro invitando a sacudir la pereza:

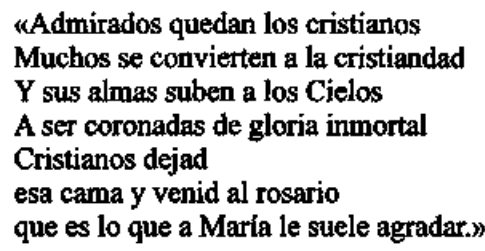

Hasta tenían una letra para animar a los peregrinos de Santiago. ¿Es que también pasaban por Villafranca? Sí sefior. Aparte de los cuatro caminos franceses que confluyen en Puente La Reina, había otras rutas menores entre las que 
se encontraba la de la Ribera, que desde Tudela se dirige a Logroño o bien sube hacia Olite, para enlazar con otro de los importantes caminos secundarios, la ruta del valle de Aibar. La copla dice así:

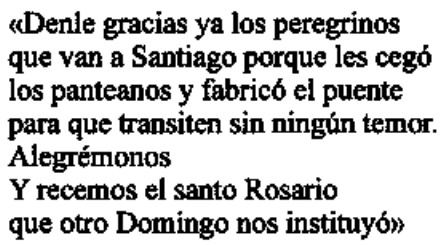

Algún lector se sorprenderá del último verso. La explicación es sencilla : esta letrilla corresponde al 14 de mayo y dos días antes se había celebrado la fiesta de Santo Domingo de la Calzada que terminaba con el mismo estribillo de los dos últimos versos, como al día siguiente. Esta habilidad la repite el autor con frecuencia, simplificando su trabajo de invención diaria y facilitando la memorización del mismo.

$\mathrm{Si}$ alguna vez no salen las cosas bien, no hay que desanimarse y tener coraje en el sufrimiento. A esto nos invita la copla siguiente que estaba preparada para el domingo siguiente, después de San Fermin. ¿Será porque después de la fiesta con frecuencia viene el tío Paco con la rebaja?

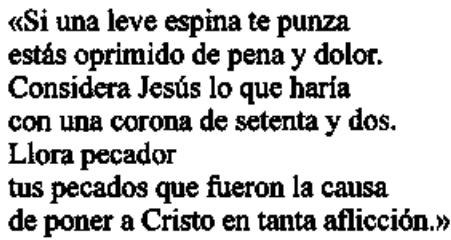

Los auroros, sin proponérselo hacian también de barómetro y el vecino cobijado en su cama, sabía por ellos el clima que le aguardaba:

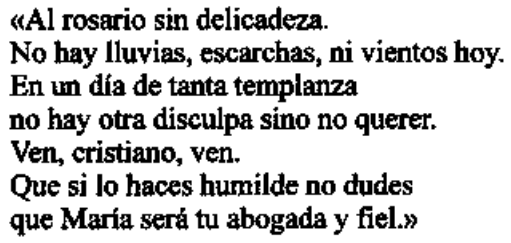

Pamplona 16 de marzo de 1998 